\title{
Scope of Mix-method studies in Pharmacy Practice Research
}

\author{
Mohamed Azmi Hassali' ${ }^{*}$, FahadSaleem¹, Maryam Farooqui ${ }^{2}$, Tahir Mehmood Khan ${ }^{3}$ \\ 1Discipline of Social and Administrative Pharmacy, School of Pharmaceutical Sciences, University Sains Malaysia, Penang, Malaysia \\ ${ }^{2}$ Faculty of Pharmacy Universiti Teknologu MARA (UiTM), Bertam Campus, Penang, Malaysia \\ ${ }^{3}$ School of Pharmacy Monash University, Bandar Sunway, Selangor, Malaysia.
}

\begin{abstract}
Conducting pharmacy practice research is particularly challenging owing to the varied approaches and methods available. While quantitative methodology has been traditionally endorsed as the more scientific method of research, there is a growing recognition for qualitative inquiry in the field of pharmacy practice research in the past few decades. Hence, the scope of this paper is to provide an overview on how to apply mixed methodology in pharmacy practice research and to discuss some of the benefits and challenges in employing mixed method. A review of the recent qualitative research done in developing countries was done. A data base search in PubMed ${ }^{\circledR}$ and an open Google ${ }^{\circledR}$ open search were done to identify the mix methods research done in pharmacy practice. Articles identified were included and their findings were described in the results section. It is seen that combining both qualitative and quantitative methodologies can provide a more complete analysis when exploring complex research questions related to pharmacy practice. Although quantitative and qualitative methods are different, one approach is not superior to the other; both have recognized strengths and weaknesses. Using mix methods create relevant and distinctive modes of enquiry in research and help the unification rather than the division of research patterns. Within this context, the field of pharmacy practice research is huge. Mix methods are meant to enrich research in pharmacy practice.
\end{abstract}

Key words: Pharmacy Practice, Mixed Methodology, Quantitative, Qualitative.

\section{INTRODUCTION}

In the current era of rapid change in healthcare delivery, the pharmacy profession is experiencing significant growth and development. Increase in health demands with an everlasting and complex range of medicines, and poor adherence to prescribed medicines have shifted the pharmacists' role towards a patient centred approach. ${ }^{1}$ Direct contact with patients and other health care providers help to achieve maximum therapeutic results. The paradigm shift for pharmacy practice took shape in 1990, when Hepler and Strand introduced the term "pharmaceutical care" which emphasizes that the role of the pharmacist involves "the responsible provision of drug therapy for the purpose of achieving definite outcomes that improve a patient's quality of life". ${ }^{2}$ This was subsequently revised to "a practice in which the practitioner takes responsibility for a patients' drug related needs and is beld accountable for this commitment'. ${ }^{3}$ Over the next decade, pharmacy organizations and academic training programs around the world promoted pharmaceutical care as a philosophy and standard of provision of care for patients. ${ }^{4}$ In essence, the concept of pharmaceutical care transformed the pharmacy profession to be more accountable in patient care especially to ensure that a patient achieves positive outcomes from drug therapy. ${ }^{5}$ This promotes pharmacist as a key member of health care team who are accountable and committed to the outcome of medication therapy.

The World Health Organization (WHO) has effectively contributed in defending and
Submission Date : 30-08-2014 Revision Date : :13-11-2014 Accepted Date : :23-12-2014

DOI: $10.5530 /$ ijper.49.2.3 Correspondence Address Mohamed Azmi Hassali Discipline of Social and Administrative Pharmacy, School of Pharmaceutical Sciences, Universiti Sains Malaysia, Penang, Malaysia Email:azmihassali@usm.my

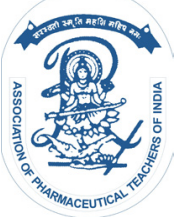

www.ijper.org 
expanding the professional roles of pharmacists. For instance, WHO has proposed a unique role for pharmacists, particularly in quality assurance and the safe and effective administration of drugs. ${ }^{1}$ Future pharmacists, the organization further noted, must also be equipped with specific knowledge, attitudes, skills and behaviours in order to practice effectively in the society. ${ }^{1,6}$ They should also be held accountable for the cost, quality and results of pharmaceutical care provided to patients. Pharmacists also act as advisors to physicians and nurses and contribute in policy decisions. ${ }^{7}$

While the level of pharmacists' involvement in provision of healthcare varies across different parts of the world, the scope of pharmacy practice remains vast and encompasses one or more of the following:

- Interpretation, evaluation and dispensing of prescription for medicinal purpose;

- Participation in medicinal product selection, medicinal product administration, medicinal product regimes and research;

- Provision of patient counselling, patient care services, clinical pharmacy services and promotion of rational use of medicinal products;

- Retailing, storing, dispensing, sale or supply of medicinal products;

- Importing, exporting, manufacturing or wholesaling of medicinal products;

- Ensuring the safety, efficacy and quality of medicinal products

\section{Pharmacy Practice Research}

In order to promote safe and rational use of medicine, the discipline of pharmacy practice need to take into consideration various issues such as the prevailing policies within the country, the economic, social and cultural context of the population, as well as the ever changing needs and expectations of the society. ${ }^{8,9}$ All these issues had steer way for the conception and execution of a large number of pharmacy practice researches in the past few decades. In addition, owing to the multidisciplinary nature of healthcare these days, pharmacy practice research has called upon collaborations between other healthcare professionals, economists, sociologists as well as members of the public. This has also led to the adoption of various methods and approaches from different disciplines.

Pharmacy practice researches are important because it is used to inform, support and adapt services to better cater for the health and pharmaceutical needs of its people. However, conducting pharmacy practice research is a challenging task owing to, among many other factors, the diverse range of research approaches and methods. Broadly, research methods in pharmacy practice are classified into qualitative and quantitative methods. Although previously regarded as two incompatible methodologies, recently, the merge of both quantitative and qualitative methodology termed as "mixed method" has become increasingly popular in areas of health research. Hence, the scope of this paper is to provide an overview on how to apply mixed methodology in pharmacy practice research and to discuss some of the benefits and challenges in employing mixed method.

\section{MATERIALS AND METHODS}

A review of the recent qualitative research done in developing countries was done. A data base search in Pub Med ${ }^{\circledR}$ and an open Google ${ }^{\circledR}$ open search were done to identify the mix methods research done in pharmacy practice. Articles identified were included and their findings were described in the results section.

\section{RESULTS}

Quantitative methods typically involve procedures to quantify phenomena, associations or relationships between variables as well as for proving or disproving a hypothesis. The process of measurement is central to quantitative research and findings are often presented as a summary of figures from various statistical procedures employed. In the field of pharmacy practice research, for example, a researcher might be interested in measuring and studying the relationship between diabetes knowledge, medication adherence and gylcemic control among diabetic patients. ${ }^{10}$ In this case, knowledge is expressed numerically in terms of scores and the causal associations or relations with medication adherence and glycemic control is then investigated by applying descriptive and inferential statistical methods. Having established that patients' knowledge about diabetes is associated with better medication adherence and better glycemic control, interventions to improve clinical outcome in diabetic patients can then focus at the educational level.

\section{Survey as Quantitative Research}

Quantitative method using survey is common in pharmacy practice research. They are especially useful for non-experimental descriptive designs that seek to illustrate reality and can be used to collect information on perception, attitude, behaviour, knowledge and belief of the respondents using a questionnaire. ${ }^{11}$ A questionnaire 
is an instrument consisting of a series of questions and/ or statements designed to elicit responses, which can be converted into measures of variables under investigation. ${ }^{12}$ For example, a researcher might be interested in assessing the acceptance and perception towards generic medicines among physicians..$^{13}$ Using a postal questionnaire, respondents were asked a series of questions and/or attitude and opinion statements designed to elicit responses, which can then be converted into measures of variables under investigation. By tabulating the responses, information on the knowledge and perception of physicians towards generic medicines are elucidated and can highlight the need for a change at the policy level.

\section{Types of survey}

Surveys come in a wide range of forms and can be classified into three types: written, oral and electronic. ${ }^{14}$ Written surveys are further divided into mail surveys, self-administered or group-administered questionnaires, interviewer-administered questionnaires and drop-off surveys. ${ }^{14}$ In order to successfully conduct a survey, the issues that must be predetermined are the practicality of access to the survey by potential respondents, the cost of the survey and the time needed to complete to whole process of the survey.

Self-administered survey is one of the more common survey employed in pharmacy practice research. There are two types of self-administered questionnaires: supervised and unsupervised. The former involves people answering in the presence of the surveyor and the latter permits the respondents to complete the questionnaires by themselves. ${ }^{15}$ The advantages of self-administered or group-administered questionnaires are numerous, which include the lower cost compared to other survey methods. ${ }^{15}$ They also allow wider geographical coverage, larger samples and wider coverage within a sample population. Furthermore, self-administered questionnaires are much easier to implement than other kinds of surveys because fewer personnel are required for data collection since there is no need for interviewers. ${ }^{15}$ The researcher is able to collect the survey results in a short space of time, ensuring a very high response rate. ${ }^{15,16}$ People too, are more likely to give complete and truthful information on sensitive topics in self-administered surveys rather than in interviews. One of the disadvantages of this approach is the time and effort involved in delivering and collecting the questionnaire. However, the benefits of being able to access potential respondents, cost-effectiveness and ability to yield a high response rate supersede the limitations when compared to other survey methods.
While quantitative methodology may present itself as a truly scientific method with rigour and robustness, it tends to obscure the reality of a phenomenon because it underestimates and neglects the non-measurable factors, which may be important all together.

\section{Qualitative methodology}

A qualitative research is exploratory in nature. Given its interactive approach, it allows identification of all possible explanations of a particular phenomenon of interest such as the identification of barriers and facilitators to change. ${ }^{17-19}$ As such, qualitative method is often referred to as a hypothesis generating method. It has also been regarded as an important tool in understanding the emotions, perceptions and actions of people, since the reason for a particular type of behaviour can be understood more clearly when it is observed and inquired about. The in depth understanding gained from a qualitative inquiry therefore enables more relevant health policies to be developed. ${ }^{20}$

\section{Types of interviews}

In qualitative research, interview is the most common form of data collection method. ${ }^{11,19,21}$ During interview, researchers seek to assess participants' understanding of the world and their experiences in detail, and to give their perspectives and interpretations of these experiences. ${ }^{20}$ The interviews are designed to produce data that are relevant to the research question of the study and can be in the form of a structured, unstructured or semi structured interview. ${ }^{22,23}$

Semi-structured interviews are conducted on the basis of a loose structure consisting of open ended questions that define the area to be explored while maintaining a flexible agenda. ${ }^{22,24}$ The interview guide in semi-structured interviews serves as a check list and ensures that the same scope of information is obtained from different participants. Within the list of the subject area, the researcher is free to pursue the question in depth. ${ }^{24}$ Semi-structured interviews are preferred when one is conducting research with people who may feel intimidated or confused by formal questioning; when researchers need to prove beyond a simple answer and also provide an opportunity for clarification of ambiguous replies and to explore, more deeply, the respondents' perceptions and views on these matters especially when there is no previous research available or very little guidance is provided to highlight a particular issues at hand. ${ }^{24,25}$

\section{Sampling in qualitative research}

While researcher conducting a quantitative research is very much concerned with probability sampling ${ }^{11,19}$ to enhance statistical rigor, researcher employing qualita- 
tive method is presented with research questions that cannot be answered by a probability sampling technique. Within this context, researchers have discussed the use of two important principles in guiding qualitative sampling. ${ }^{25}$ The first principle is based on appropriateness where participants who can best inform the research according to the demand of the study.

In qualitative research, there are no published guidelines or tests of adequacy for estimating the sample size; the required sample size is estimated to reach the saturation point equivalent to formulae used in quantitative research where the signals of the saturation point is determined by the researchers, depending on the adequateness of the results, i.e., they make sense and do not have gaps. ${ }^{24,26}$ The five most common categories of non-probability sampling methods used in qualitative research are purposive sampling, convenience sampling, snowball sampling, theoretical sampling and quota sampling. ${ }^{19,24,25}$

\section{Data management and analysis in qualitative research}

The volume of data gathered from a qualitative inquiry is enormous. Data are usually in the form of textual narrative that are transcribed generally verbatim from the tape-recording, written descriptions of observations such as field notes, and reflections, ideas, and conjectures recorded by the researcher. ${ }^{19,24}$ As such, qualitative research is often subject to criticism regarding its validity and reliability. ${ }^{27-28}$ The specific processes that researchers actually undertake to achieve validity in qualitative research are rarely described in the literature, ${ }^{29}$ however, qualitative research, and the process of analysis in particular, involve continuous reflexivity and self-scrutiny. ${ }^{29}$

\section{DISCUSSION}

In qualitative inquiry, the study objectives are more likely to be exploratory. ${ }^{11}$ The direction and the content of the interview are, therefore, guided by the responses of the interviewee rather than by following the agenda of the researcher. ${ }^{11}$ Validation of qualitative analysis can be performed in three ways. ${ }^{27}$ the first is communicative validation that involves the researchers returning to the field to collect additional data to verify or further develop their findings; the second is argumentative validation in which an attempt is made to use the data set to argue a contradictory viewpoint; and the third way of validating qualitative data is by using cumulative validation whereby the researchers may use the literature to demonstrate how their findings are consistent with existing knowledge of the subject. ${ }^{17}$ The main way in which qualitative researchers ensure reliability of their analyses is by maintaining meticulous records of the interviews and observations through documenting the process of analysis in detail. ${ }^{27}$ Thus, qualitative research depends, particularly for its validity, on the skills, training, insights and capabilities of the researcher at every stage. $^{24}$

In the work of Long and colleagues, researchers had employed qualitative methodology to explore the experiences of heart failure patients towards managing their medical conditions and to determine facilitators and barriers contributing to the process of quality use of medicines among them. ${ }^{30}$ While it is an established fact that the management of heart failure is often complicated by patients' adherence to diet, fluid restriction and medication, little is known about the factors affecting adherence from the patients' perspective. This unique approach gave rise to very rich data that is otherwise not captured in the conventional quantitative research. The findings of this study had allowed the development of a more relevant modular patient counselling program called medication therapy adherence program used in the heart failure clinic.

The appeal in the integration of both qualitative and quantitative methodology in pharmacy practice research lies in the possibility that it can broaden the perspective of a research and unravel the complexity of the many different factors that influence health. Research designs for mixed method research generally falls into two main group namely concurrent and sequential designs depending on the purpose of employing a mixed methodology. ${ }^{31}$ Qualitative and quantitative methods are employed concurrently in an attempt to compare and validate data collected from both methods, a process known as triangulation or expansion. ${ }^{31}$ Usually in this design, the same individuals provide both the qualitative and quantitative data.

When qualitative and quantitative methods are used sequentially, the first informs the analysis of the second. In the sequential design, a preliminary qualitative study may precede a larger quantitative study where the qualitative method provides complementary assistance to the quantitative research that follows. ${ }^{32}$ For example, findings from in-depth interviews and focus group discussion could be used to develop the content of a questionnaire. Such combination of methods ensures that important topics are covered in the questionnaire to improve the effectiveness of the survey. ${ }^{33,34}$ Having identified the gaps in the knowledge on adverse drug reaction reporting among community pharmacists from a qualitative inquiry, Elkalmi and colleagues conducted a larger scale survey with final year pharmacy undergraduate students enrolled in 5 different universities in an attempt to evaluate the need for the inclusion of pharmacovigilance into the current pharmacy curriculum. Extending the use of mix methodology in developing 
countries, Salem et al conducted in-depth interviews and focus group discussion to evaluate self management of hypertension and assessment of perception towards medication use among hypertensive patients. ${ }^{35,36}$ Based on findings, an educational intervention was provided to hypertensive patients aiming to modify drug taking attitude, medication adherence and self management of hypertension.

By the same logic, a preceding quantitative method could also guide the execution of a qualitative research to provide a much richer understanding or a certain phenomena or pattern. For example, Liau et al used a qualitative method to assess the quality and effectiveness of a work site health promotion intervention targeting cardiovascular risk factors such as smoking, obesity, physical inactivity and unhealthy diet. ${ }^{37} \mathrm{By}$ using findings from the follow up qualitative inquiry, researchers gained a deeper insight into the ways to improve the intervention that is otherwise unable to be captured from the quantitative arm. An important assertion that needs to be made here is that neither of these designs is implying superiority or inadequacy of either qualitative or quantitative methodology but rather to focus on how to make complementary uses of both methods to fill out, complete or extend the information. In nutshell qualitative research not only assist in generating a deeper insight about the problem

\section{REFERENCES}

1. World Health Organization New tool to enhance role of pharmacists in health care. http://www.who.int/mediacentre/news/new/2006/nw05/en/index.html; 1996.

2. Hepler CD, Strand LM, Opportunities and responsibilities in pharmaceutical care. American Journal of Hospital Pharmacy. 1990; 47(3): 533-43.

3. Strand LM. Re-visioning the profession. Journal of American Pharmacists Association 1997; 37: 474-8.

4. Farris KB, Fernando F, Benrimoj SI. Pharmaceutical care in community pharmacies: practice and research from around the world. Annals of Pharmacotherapy 2005; 39(9): 1539-41

5. Rosemin K. Evaluation of pharmaceutical care opportunities within an advanced pharmacy practice experience. American Journal of Pharmaceutical Education 2006 70(3): 1-9.

6. Zammit D. How to make ethical decisions. The Pharmaceutical Journal 2003; 271: 468.

7. Azhar S, Hassali MA, Ibrahim MI, Ahmad M, Masood I, Shafie AA. The role of pharmacists in developing countries: the current scenario in Pakistan. Human Resource for Health 2009; 13(7): 54.

8. Harding G, Taylor K. Social dimension of pharmacy, the social context of pharmacy. The Pharmaceutical Journal 2002; 269 395-7.

9. Rickles NM, Albert IW, Smith MC. Social and Behavioral Aspects of Pharmaceutical Care. Sudbury MA: Jones and Bartlett Publishers; 2009.

10. Al-Qazaz HK, Sullaiman SAS, Hassali MA, Shafie AA, Sundram S, AI-Nuri $\mathrm{R}$, et al. Diabetes knowledge, medication adherence and glycemic control among patients with type 2 diabetes. International Journal of Clinical Pharmacy 2011; 33(6): 1028-35.

11. Punch KF. Introduction to social research: quantitative and qualitative approaches. Thousand Oaks, California: Sage Publications; 2005.

12. Gray DE. Doing research in the real world. Thousand Oaks, California: Sage Publication; 2009. in discussion, but also assist in identifying the potential ways to improve and intervene the issues in pharmacy practice research. ${ }^{38-43}$

\section{CONCLUSION}

To conclude, although quantitative and qualitative methods are different, one approach is not superior to the other; both have recognized strengths and weaknesses. Using mix methods create relevant and distinctive modes of enquiry in research and help the unification rather than the division of research patterns. Within this context, the field of pharmacy practice research is huge. 38-42 Given that approaches and research methods are diverse and that all methods have their own strength and weaknesses, employing mixed methodology approach may be feasible and more effective in giving a complete analysis of the issues in pharmacy practice research. Depending on the researcher's motivations, each of these methodologies can be exploited and combined to give a broader perspective of a particular research question. Mix methods are meant to enrich research in pharmacy practice.

\section{COMPETING INTERESTS}

The authors declare that they have no competing interests.

13. Chua GN, Hassali MA, Shafie AA, Awaisu A. A survey exploring knowledge and perceptions of general practitioners towards the use of generic medicines in the northern state of Malaysia. Health Policy 2010 95(2): 229-35.

14. Salant P, Dillman D. How to conduct your own survey. New York: John Wiley \& Sons Inc; 1994

15. Bourque L, Fielder E. How to conduct self-administered and mail surveys. Thousand Oaks, California: Sage Publications Inc; 2003.

16. Fink A, Kosecoff J. How to conduct surveys. Thousand Oaks, California: Sage Publications Inc; 1998.

17. Smith F. Research methods in pharmacy practice. Pharmaceutical Press, London; 2002.

18. Starks H, Trinidad SB. Choose your method: a comparison of phenomenology, discourse analysis, and grounded theory. Qualitative Health Research 2007 17(10): 372-80.

19. Berg B. Qualitative research methods for the social sciences Vol 5. Boston: Allyn and Bacon; 2004.

20. Holloway I. Qualitative research in health care. Berkshire England: Open University Press; 2005.

21. Thorne S. Data analysis in qualitative research. Evidence Based Nursing 2000; 3(3): 68-70.

22. Britten N. Qualitative research: qualitative interviews in medical research. British Medical Journal 1995; 311(6999): 251-3.

23. Richards L, Morse JM. User's Guide to Qualitative Methods. Thousand Oaks, California: Sage Publications; 2007.

24. Patton M. Qualitative research and evaluation methods. Thousand Oaks, California: Sage Publications Inc; 2002.

25. Morse J, Field A. Qualitative Research Methods for Health Professionals. Thousand Oaks, California: Sage Publication; 1995.

26. Morse J. The significance of saturation. Qualitative Health Research 1995; 5(2): $147-9$ 
27. Mays N, Pope C. Qualitative research: rigour and qualitative research. British Medical Journal 1995; 311(6997): 109-112.

28. Kirk J, Miller ML. Reliability and validity in qualitative research. Beverly Hills: Sage Publications Inc; 1986.

29. Pyett PM. Validation of qualitative research in the Real World. Qualitative Health Research 2003; 13(8): 1170-9.

30. Ming CL,Hassali MA, Shafie AA, Awaisu A, Hadi AM, Al-Haddad M. Perspectives of heart failure patients in Malaysia towards medications and disease state management: findings from a qualitative study. Journal of Public Health 2010; 19(6): 569-77.

31. Greene CJ, Caracelli JV. Advances in mixed-method evaluation: The challenges and benefits of integrating diverse paradigms. San Francisco Jossey-Bass; 1997.

32. Adamson J, Gooberman-Hill R, Woolhead G, Donovan J. 'Questerviews': using questionnaires in qualitative interviews as a method of integrating qualitative and quantitative health services research. Journal of Health Services Research \& Policy 2004; 9(3): 139-45.

33. Elkalmi RM, Hassali MA, Ibrahim MI, Widodo RT, Efan QM, Hadi MA. Pharmacy Students' Knowledge and Perceptions About Pharmacovigilance in Malaysian Public Universities. American Journal of Pharmaceutical Education 2011; 75(5): 96.

34. Elkalmi RM, Hassali MA, Ibrahim MI, Shafie AA. A qualitative study evaluating perception of community pharmacist towards ADRs reporting in northern Malaysia. Drug Safety 2009; 32(1): 878

35. Saleem F, Hassali MA, Shafie AA, Atif M. Drug attitude and adherence: A qualitative insight of patients with hypertension. Journal of Young Pharmacists 2012; 4(2): 101-7.

36. Saleem F, Hassali MA, Shafie AA, Bashir S, Atif M. Perceptions of disease state management among Pakistani hypertensive patients: Findings from a focus group discussion. Tropical Journal of Pharmaceutical research 2011 10(6): $833-40$

37. Liau SY, Hassali MA, Shafie AA, Ibrahim MI. Assessing quality of a worksite health promotion programme from participants views: findings from a qualitative study in Malaysia. Health Expectations 2011; 17(1): 116-28.

38. Emeka, P. M., Al-Omar, M. J., \& Khan, T. M. (2012). A Qualitative Study Exploring Role of Community Pharmacy In The Irrational Use And Purchase of Non-prescription Antibiotics In Al Ahsa. Eur J Gen Med, 9(4), 230-234.

39. Khan, T. M., \& Ibrahim, Y. (2013). A qualitative exploration of the nonprescription sale of drugs and incidence of adverse events in community pharmacy settings in the Eastern Province of the Kingdom of Saudi Arabia.European Journal of Hospital Pharmacy: Science and Practice, 20(1):26-31.

40. Azhar, S., Hassali, M. A., Izham, M. I., \& Khan, T. M. (2010). A Qualitative Evaluation of Nurses' Perception towards the Role of Pharmacist in Healthcare Setup in Pakistan. HealthMed,4(1):71-76.

41. Wong, Z. Y., Hassali, M. A., Yahaya, A. H., Saleem, F., Aljadhey, H., \& Khan, T. M. (2014, October). A Qualitative Study Exploring Perspectives towards Generic Medicines among Medical Specialists and Consultants at a District Hospital in Malaysia. In Pharmacoepidemiology And Drug Safety 23:120-121.

42. Hassali, M. A., Ching, M. W., Yusoff, Z. M., Hussein, Z., Alrasheedy, A. A., AL-Tamimi, S. K., ... \& Khan, T. (2014). 'Why I do not want to take insulin shots': Findings from a qualitative study among diabetic patients in Malaysia. Journal of Public Health, 22(1), 3-11.

43. Khan, T. M., Shahzad, C. M., Ahmed, M. K., \& Azhar, S. (2012). Attitudes of Emergency Department Staff towards the Role of Clinical Pharmacists in a Region of Saudi Arabia-A Pilot Study. Tropical Journal of Pharmaceutical Research, 11(3), 477-483. 